\title{
Psychometric properties of the Brazilian version of the Cognitive Emotion Regulation Questionnaire
}

\author{
Propriedades psicométricas da versão brasileira do Questionário de Regulação \\ Emocional Cognitiva
}

Julia Luiza Schäfer, Bolivar Ramos Cibils Filho, Tayse Conter de Moura, Valquíria Coutinho Tavares, Adriane Xavier Arteche, Christian Haag Kristensen

\begin{abstract}
Introduction: The Cognitive Emotion Regulation Questionnaire (CERQ) was developed to measure nine cognitive strategies referring to what someone thinks after the experience of threatening or stressful events. The main purpose of this study was to evaluate the validity of the Brazilian version of the CERQ.

Methods: The adaptation process included translation, backtranslation, expert committee evaluation, and test on 30 participants from the target population. A sample of 445 university students completed the Portuguese version of the CERQ, a sociodemographic questionnaire, the Life Events Checklist (LEC-5), and the Positive and Negative Affect Schedule (PANAS) on an on-line research platform. Validity was assessed through confirmatory factor analysis of two models - a ninefactor model and a second-order model. Internal consistency was assessed through Cronbach's alpha analysis and correlations with affective variables measured by the PANAS.

Results: The analyses showed that the nine-factor model of the CERQ has good factorial validity and high reliability, with Cronbach's alpha values ranging between 0.71 and 0.88 . The second-order model did not have a good fit to the data.

Conclusion: The results obtained in this study are similar to the ones found previously, indicating that the Brazilian version of the CERQ is a valid and reliable tool for assessing cognitive emotion regulation strategies, but that grouping them according to their adaptability is not recommended.
\end{abstract}

Keywords: Emotion regulation, cognitive emotion regulation, Cognitive Emotion Regulation Questionnaire, psychometric properties, cognitive psychology.

\section{Resumo}

Introdução: O Questionário de Regulação Emocional Cognitiva (Cognitive Emotion Regulation Questionnaire [CERQ]) foi desenvolvido para medir nove estratégias cognitivas que se referem à forma como as pessoas pensam sobre a experiência de eventos ameaçadores ou estressantes. O objetivo principal deste estudo foi desenvolver e avaliar a validade da versão brasileira do CERQ.

Métodos: O processo de adaptação incluiu tradução, retrotradução, avaliação de comitê de especialistas e teste em 30 participantes da população-alvo. Uma amostra de 445 universitários completou a versão em português do CERQ, um questionário sociodemográfico, a Lista de Verificação de Eventos de Vida (Life Events Checklist [LEC-5]) e a Escala de Afeto Positivo e Negativo (Positive and Negative Affect Schedule [PANAS]) em uma plataforma de pesquisa online. A validade do instrumento foi avaliada através da análise fatorial confirmatória de dois modelos: um modelo de nove fatores e um modelo de segunda ordem. A consistência interna foi avaliada por meio da análise de alfa de Cronbach e correlações com variáveis afetivas medidas pela PANAS.

Resultados: As análises mostraram que o modelo de nove fatores do CERQ possui boa validade fatorial e alta confiabilidade, com valores de alfa de Cronbach variando entre 0,71 e 0,88. 0 modelo de segunda ordem não se ajustou bem aos dados.

Conclusão: Os resultados obtidos neste estudo são semelhantes aos encontrados em estudos anteriores, indicando que o CERQ é uma ferramenta válida e confiável para avaliar as estratégias de regulação cognitiva das emoções, mas que agrupá-las de acordo com sua adaptabilidade não é recomendado.

Descritores: Regulação emocional, regulação emocional cognitiva, Questionário de Regulação Emocional Cognitiva, propriedades psicométricas, psicologia cognitiva.

Pontifícia Universidade Católica do Rio Grande do Sul (PUCRS), Porto Alegre, RS, Brazil.

Submitted Jun 04 2017, accepted for publication Jan 112018.

Suggested citation: Schäfer JL, Cibils Filho BR, de Moura TC, Tavares VC, Arteche AX, Kristensen CH. Psychometric properties of the Brazilian version of the Cognitive Emotion Regulation Questionnaire. Trends Psychiatry Psychother. 2018;40(2):160-169. http://dx.doi.org/10.1590/2237-6089-2017-0074 


\section{Introduction}

Emotions play an important role in the individuals' adaptation to various aspects of everyday life. ${ }^{1}$ The ability to influence their occurrence, intensity, duration and expression, known as emotion regulation, ${ }^{2}$ can be critical when dealing with significant levels of stress. ${ }^{3}$ Cognitive emotion regulation (CER), i.e., emotion regulation through cognitive processes, can contribute to emotional control, ${ }^{4}$ and refers to the conscious way of dealing with information that elicits emotions. Its study has focused on attentional control and cognitive responses employed to modify the impact or meaning of an emotional stimulus, the emotional experience itself, ${ }^{5}$ or the intensity and quality of an emotional response. ${ }^{6}$

A great variety of CER strategies have already been associated with mental health outcomes and discussed as playing an important role in some clinical disorders, ${ }^{7}$ such as anxiety and depression, ${ }^{5,8}$ acute stress, ${ }^{9}$ somatic complaints, $^{10}$ and posttraumatic stress symptoms. ${ }^{11}$ In order to carry out investigations to uncover the importance, impact, and individual differences in regulating emotions through cognitive processes, the development and dissemination of adequate measure instruments are crucial. ${ }^{4}$

Among some possible ways of assessing CER, the Cognitive Emotion Regulation Questionnaire (CERQ) is an instrument that measures nine cognitive strategies that refer to ways people think and deal with emotions that follow negative life events, ${ }^{4}$ such as those that inflict a life threat, or that generate high levels of acute and chronic stress. Strategies are classified as adaptive or maladaptive according to their positive and negative associations with clinical disorders. ${ }^{5,8}$ The maladaptive strategies measured by the CERQ are: 1) self-blame (thoughts about being the one to blame for the negative experience); 2) other-blame (thoughts about the others being the ones to blame for the negative experience); 3 ) rumination (excessive focus on thoughts associated to the negative aspects of the experience); and 4) catastrophizing (thoughts emphasizing the terror of the negative experience). On the contrary, the adaptive strategies measured by the instrument are: 1) putting into perspective (thoughts relativizing the experience and putting aside its seriousness when comparing it to other experiences); 2) positive refocusing (more pleasant and joyful thoughts instead of thoughts about the negative experience); 3) positive reappraisal (thoughts about giving a new positive meaning to the experience in terms of personal goals); 4) acceptance (thoughts about accepting the experience); and 5) refocus on planning (thoughts about which steps are necessary to be taken to deal with the negative experience). ${ }^{4,5}$
The questionnaire consists of 36 items divided equally into the nine factors, or strategies, described above. Participants rate, using a 5-point Likert scale ( 1 =almost never to 5 =almost always), how frequently they think in a certain way when generally or specifically experiencing a negative, threatening, or stressful life event. Each factor yields a mean; the higher the mean, the more frequent the use of the strategy in response to a negative event. ${ }^{5}$ In addition to the score produced by the nine factors, it is also possible to obtain secondorder scores for adaptive and maladaptive CER. The original version of the instrument has been translated and validated to the Romanian, ${ }^{12}$ Argentinean, ${ }^{13}$ Peruvian, ${ }^{14}$ Persian, ${ }^{15}$ French, ${ }^{16}$ Turkish, ${ }^{17}$ Spanish, ${ }^{18}$ and Chinese ${ }^{19}$ populations.

Identifying CER strategies may be extremely important considering that they have the potential to neutralize negative experiences and decrease the physiological activation caused by strong emotional reactions. ${ }^{1}$ Because the CERQ may be a recommended instrument to understand individuals' CER processes, the purpose of this paper was to cross-culturally adapt and validate its Brazilian version.

\section{Method}

\section{Participants}

The sample of this study comprised 445 university undergraduate $(92.1 \% ; n=410)$ and graduate $(7.9 \%$; $\mathrm{n}=35$ ) students from a private university in the city of Porto Alegre, state of Rio Grande do Sul, southern Brazil. Within the sample, $56.6 \%(n=252)$ were female, and the mean age was 22.7 years (standard deviation $[S D]=4.4)$. The mean family income of the sample was within the range considered upper middle class (family monthly income ranging from $\mathrm{R} \$ 8,800.01$ to $\mathrm{R} \$ 17,600.00)$, according to Brazilian standards. ${ }^{20}$ Most of the students were single $(90.3 \% ; n=402)$ and lived with their parents $(49.4 \% ; n=220)$. Exposure to traumatic and stressful events was assessed using the Life Events Checklist (LEC-5), and 91.6\% $(n=408)$ of the participants selected a traumatic event as the worst event they had been exposed to during their lifetime. Events were considered traumatic according to the definition of the Diagnostic and Statistical Manual of Mental Disorders, 5th edition (DSM-5), under the Trauma and Stress Related Disorders chapter. ${ }^{21}$

Participants were recruited in a non-random fashion through social media (Facebook), e-mails, and posters spread around the university campus where the present research took place. Students who reported that they had not been through any stressful or traumatic 
event, and those who reported a given diagnosis of developmental or neurological diseases, were excluded from the sample.

\section{Measures}

In addition to the CERQ, three other instruments were applied to evaluate sociodemographic variables of interest, exposure to traumatic events, and affective state variables. Participants were asked to answer the CERQ keeping in mind the negative or traumatic life event that had the biggest impact in their lives. Therefore, in this study, the CERQ was used to evaluate how the participants coped with a specific self-reported negative or traumatic life event.

\section{Sociodemographic characteristics}

For sociodemographic variables, an instrument was developed by the authors consisting of questions covering general information on the participant's age, gender, education, profession, and family income. It also included questions about the participant's history of previous psychiatric disorders, in order to assess the exclusion criteria of the study.

\section{Exposure to stressful and traumatic events}

The LEC, ${ }^{22}$ adapted in accordance to the DSM $-5,{ }^{23}$ was used to assess the participant's exposure to stressful and traumatic events in order to select the event that had had the biggest impact in their lives. The LEC- 5 consists of two complementary parts. The first one contains 17 items referring to different types of traumatic events (car accident, assault, fire, grief, etc.). The participant is asked to indicate, for each event, whether he or she has ever experienced, witnessed or heard about it. The second part of the instrument contains eight objective questions about the characteristics of the most traumatic event experienced, such as the date of the event, its duration, and perceived intensity. The original version of the instrument showed convergence with psychopathology measures associated with trauma exposure, such as the Clinician-Administered PTSD Scale (CAPS; $r=0.39, \mathrm{p}<0.01)$, the PTSD Checklist-Military Version (PCL-M) $(r=0.43, \mathrm{p}<0.01)$, and the Modified Post-Traumatic Stress Disorder Symptom Scale (MPSS) $(r=0.44, \mathrm{p}<0.05) .^{22}$

\section{Affective states}

The Positive and Negative Affect Schedule (PANAS), ${ }^{24}$ translated and validated for Brazilian Portuguese, ${ }^{25}$ was used to investigate the participants' affective states since they had experienced the traumatic event indicated on the LEC-5. The PANAS is a self-report scale comprised of 20 items measuring positive and negative emotional states. In this study, participants answered questions, using a 5-point Likert scale ( $1=$ never to $5=$ almost always), regarding the frequency with which they have experienced specific emotions since the exposure to the most traumatic event. Internal consistencies of both scales (positive and negative affect) in Brazilian Portuguese are considered high ( $a=0.87$ for negative affect and $a=0.88$ for positive affect).$^{25}$

\section{Procedures}

To fulfill the purpose of this study, translation and adaptation of the instrument was conducted according to published guidelines, ${ }^{26,27}$ following the steps here described. The English version of the CERQ was translated into Portuguese by two independent translators fluent in English and Portuguese, and back-translated into English by two other independent translators. Three psychologists compared the original English version of the CERQ to the back-translated versions, and the items that were closest to the original ones were selected to compose the preliminary Brazilian version of the CERQ. Four expert judges in the fields of emotion regulation, human cognition, and psychometric properties evaluated the preliminary version. After the judges' evaluation, each item was assessed using a 5-point Likert scale considering clarity of language, practical pertinence, and theoretical relevance ( $1=$ none to $5=$ completely), generating a coefficient validity index (CVI) for each dimension. The judges' suggestions were taken into consideration and necessary changes were made for the final version, which was, once again, showed and evaluated by the judges. Finally, the final version was tested in the first 30 subjects of the study, who were inquired about item comprehension using a 5 -point Likert scale ( $1=\mathrm{I}$ understood nothing to $5=\mathrm{I}$ understood everything).

This research study was approved by the research ethics committee of Pontifícia Universidade Católica do Rio Grande do Sul (PUCRS), Porto Alegre, RS, southern Brazil (CAAE 53519616.5.0000.5336). Participants were asked to access an Internet link that directed them to an online research platform (Qualtrics) where the instruments were to be displayed. Before the instruments could be displayed, the participants were presented with the informed consent form, which explained the study objectives and guaranteed voluntary participation and anonymity, and then had to give their consent. Participants were free to terminate their participation at any time, without any negative consequences, and those who were identified as being in any psychological suffering were contacted via e-mail to be referred to psychological treatment if they wished so. 
Through the LEC-5, participants were asked to choose, among all events to which they might have been exposed, the one that they considered the worst, or that had had the biggest impact in their lives. After choosing one event, they were asked to answer the PANAS and the CERQ according to how they had been feeling and thinking since the event happened. Events were classified using an adaptation of suggested traumatic event categories used in the literature, ${ }^{28}$ and resulted in: a) life threat to self (direct exposure to threat of death, actual serious injury, or threatened serious injury); b) life threat to others (direct or indirect exposure to threatened, or actual death, or serious injury of others); c) traumatic loss (witnessing or knowing about the death of a family member, or friend, or violent deaths of acquaintances); d) moral injury caused by others (witnessing or being a victim of an act perceived as a gross violation of moral or ethical standards); and e) moral injury caused by self (committing an act that is perceived to be a gross violation of moral or ethical standards). Frequencies of the participants' exposure to these events were, respectively, $29.7 \%(n=121), 25 \%$ $(n=102), 27.9 \%(n=114), 16.7 \%(n=68)$, and $0.7 \%$ $(n=3)$.

\section{Data analysis}

Analyses were performed using the software AMOS 20 and the Statistical Package for the Social Sciences (SPSS) version 23.0. Confirmatory factor analysis (CFA) with maximum likelihood estimation was used to obtain evidence of the instrument's construct validity testing the fit of the data to the original nine-factor model $^{5}$ and to the second-order model of adaptive and maladaptive CER dimensions ${ }^{18}$ (Figure 1). For the confirmatory factor analyses, correlations among all factors and some item errors were allowed. ${ }^{5}$ Item error correlations were allowed only within factors between those items that showed strong correlation coefficients

\section{Nine-factor model}

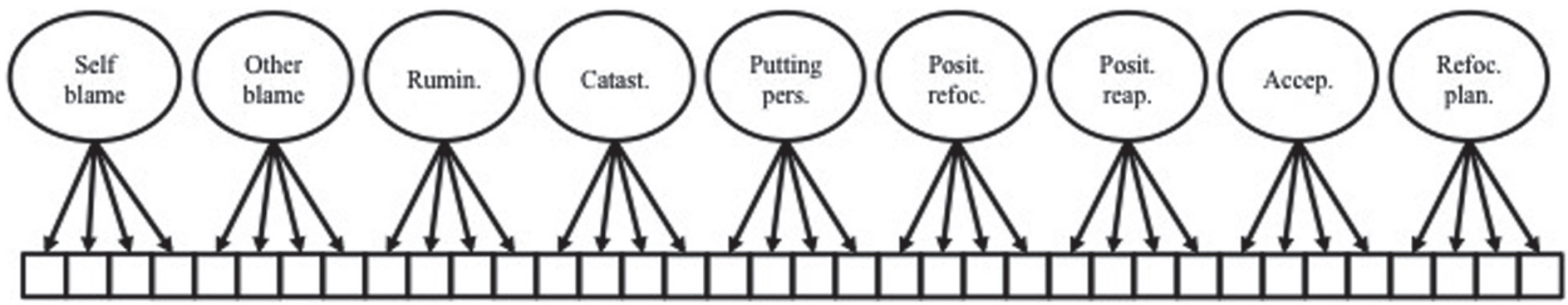

\section{Second-order model}

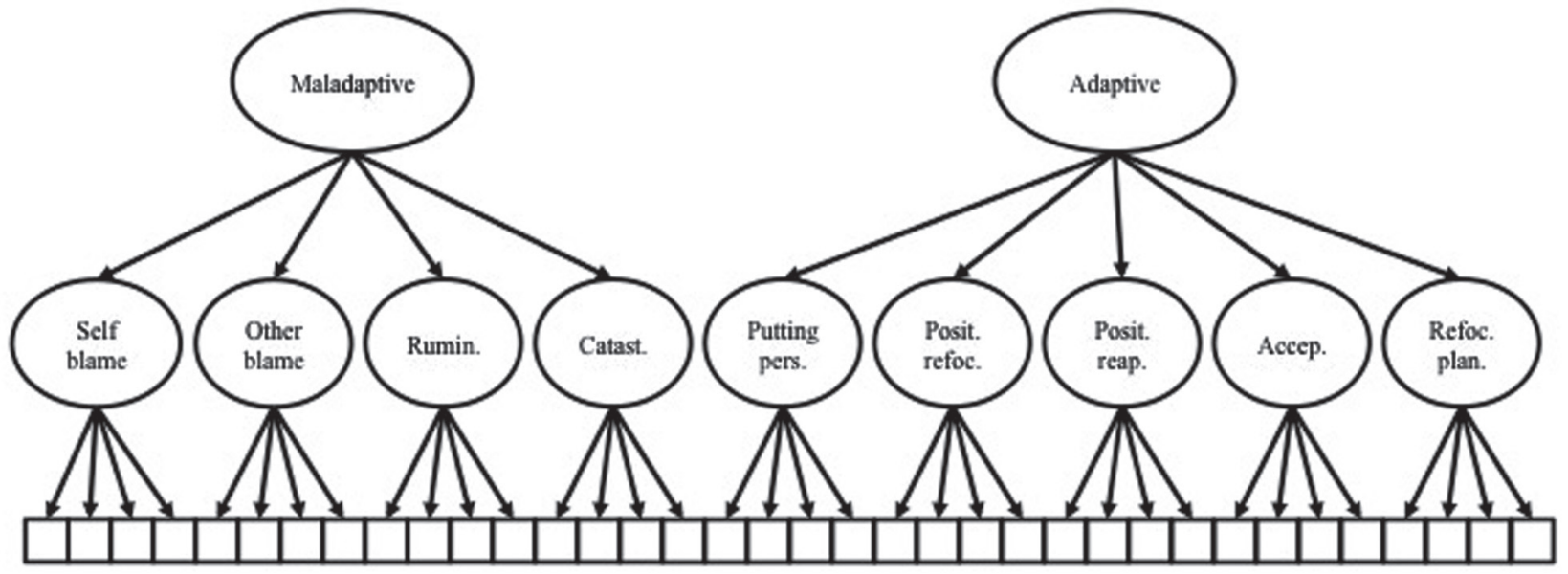

Figure 1 - The Cognitive Emotion Regulation Questionnaire models tested for data fit. Accept. = acceptance; Catast. = catastrophizing; Posit. reap. $=$ positive reappraisal; Posit. refoc. $=$ positive refocusing; Putting pers. $=$ putting into perspective; Refoc. plan. $=$ refocus on planning; Rumin. = rumination. 
(above 0.7). Model fit conclusions were drawn based on evidence and cut-off points suggested in the literature. Chi-square statistics evaluation was complemented ${ }^{29}$ by examining the standardized root mean square residual (SRMR) and the root mean square error of approximation (RMSEA). ${ }^{30}$ Additionally, the comparative fit index (CFI) was reported for possible comparisons with previous studies, and Akaike information criterion (AIC) indices were reported to compare and decide upon the most appropriate model to fit the data, since lowest AIC values are judged to fit the data better in relation to alternative solutions. ${ }^{31}$ Acceptable fit was judged based on the proposed cut-offs of $\leq 0.10$ for SRMR, ${ }^{29}$ 0.05-0.08 for RMSEA, ${ }^{30}$ and, even though a CFI value $>0.95$ is preferable, CFI values $\geq 0.90$ may indicate a reasonably good fit. ${ }^{29}$

After testing for the models' construct validity, the sample's normality distribution was evaluated, as were the means and SDs obtained on the CERQ subscales. Internal consistency of each factor of the nine-factor model was assessed using Cronbach's alpha values. Because the sample was not normally distributed for all variables, Spearman's correlations among all subscales were estimated. As suggested in previous studies, ${ }^{13,18}$ validity evidence was also assessed through the investigation of Spearman's correlations among CER strategies and positive and negative affect. Due to the already reported interrelation between the CERQ subscales, partial correlations were also obtained between each scale and positive and negative affect, in each case controlling for the effect of the remaining subscales.

\section{Results}

\section{Adaptation process}

Results from the adaptation process indicate the following CVI scores for the CERQ: a) language clarity $=0.934$; b) practical relevance $=0.948$; and c) theoretical relevance $=0.945$. The final version was tested in the target population and all items had a comprehension mean of $\geq 3$ (mean $=4.45 ; S D=0.22$ ), suggesting good comprehension. The high rates on the final total CVI scores and pre-test results in the target population demonstrated that the CERQ was adequately translated and cross-culturally adapted.

\section{Confirmatory factor analysis and factor structure}

The first model tested (model 1 ) for goodness of fit was the original nine-factor structure ${ }^{4}$ in which the items of the instrument are grouped into nine dimensions, as follows: self-blame (items 1, 10, 19, and 28), acceptance (items 2, 11, 20, and 29), rumination (items 3, 12, 21, and 30), positive refocusing (items $4,13,22$, and 31), refocus on planning (items $5,14,23$, and 32), positive reappraisal (items $6,15,24$, and 33), putting into perspective (items 7, 16, 25, and 34), catastrophizing (items 8, 17, 26, and 35), and other-blame (items 9, 18,27 , and 36). Confirmatory factor analysis provided an overall acceptable fit of model 1 to the data after modification indices were assessed and correlations among all latent variables and within-factor errors were allowed. The global fit indices obtained for the model were as follows: $X^{2}{ }_{(542)}=1,402.038 ; p<0.001 ; C F I=0.90$; RMSEA $=0.06(95 \%$ confidence interval $[95 \% \mathrm{CI}]=0.056-$ $0.064) ; \mathrm{SRMR}=0.07$; and $\mathrm{AIC}=1,650.038$. The $\mathrm{SRMR}$ and RMSEA suggest that the latent and the measurement models, respectively, are acceptable. However, the CFI of 0.90 falls a little under the acceptable cut-off of 0.95 , but right on the acceptable cut-off of 0.90 . Globally, these indices indicate acceptable fit.

In accordance with what has been described in previous studies about the association between CER strategies and psychological outcomes, a second-order factorial model was proposed and tested, ${ }^{18}$ in which the dimensions listed before were grouped into two higher order factors of adaptive (acceptance, positive refocusing, refocusing on planning, positive reappraisal, and putting into perspective) and maladaptive (selfblame, rumination, catastrophizing, and other-blame) strategies. Differently from what was expected, the CFA results for model 2 provided global fit indices out of the range of the proposed cut-offs, suggesting non-acceptable goodness of fit, even after correlations among within-factor errors were allowed. The indices for the model were: $X^{2}{ }_{(566)}=1,676.073 ; p<0.001$; $\mathrm{CFI}=0.86 ; \quad \mathrm{RMSEA}=0.07 \quad(95 \% \mathrm{CI}=0.063-0.070)$; $S R M R=0.1 ;$ and $A I C=1,876.073$. These indices indicate that the strategies are not acceptably distinguishable between adaptive and maladaptive strategies.

According to the AIC values, model 1 was chosen as the one with better and acceptable fit for the Brazilian version of the CERQ when compared to model 2. Its factor structure was kept the same as the original one; the standardized regression factor loadings of each item are presented in Table 1 . The overall standardized factor loadings were appropriate: except for items 23 and 26, all were above 0.45. Because model 2 did not show adequate indices, and showed a higher AIC than model 1 , considering the suggested grouping of adaptive and maladaptive CER strategies was not valid for this Brazilian sample.

\section{Reliability analysis}

Reliability analysis using Cronbach's alpha showed good internal consistency for all nine CERQ subscales, as 
Brazilian CERQ psychometric properties - Schäfer et al.

Table 1 - Standardized regression factor loadings of the Cognitive Emotion Regulation Questionnaire (CERQ) - Brazilian Version $(\mathrm{N}=445)$

\begin{tabular}{|c|c|c|c|c|c|c|c|c|c|}
\hline CERQ & 1 & 2 & 3 & 4 & 5 & 6 & 7 & 8 & 9 \\
\hline \multicolumn{10}{|l|}{ Self-blame } \\
\hline Item 1 & 0.87 & & & & & & & & \\
\hline Item 10 & 0.88 & & & & & & & & \\
\hline Item 19 & 0.73 & & & & & & & & \\
\hline Item 28 & 0.71 & & & & & & & & \\
\hline \multicolumn{10}{|l|}{ Acceptance } \\
\hline Item 2 & & 0.65 & & & & & & & \\
\hline Item 11 & & 0.72 & & & & & & & \\
\hline Item 20 & & 0.59 & & & & & & & \\
\hline Item 29 & & 0.81 & & & & & & & \\
\hline \multicolumn{10}{|l|}{ Rumination } \\
\hline Item 3 & & & 0.77 & & & & & & \\
\hline Item 12 & & & 0.77 & & & & & & \\
\hline Item 21 & & & 0.77 & & & & & & \\
\hline Item 30 & & & 0.85 & & & & & & \\
\hline \multicolumn{10}{|c|}{ Positive refocusing } \\
\hline Item 4 & & & & 0.74 & & & & & \\
\hline Item 13 & & & & 0.78 & & & & & \\
\hline Item 22 & & & & 0.77 & & & & & \\
\hline Item 31 & & & & 0.84 & & & & & \\
\hline \multicolumn{10}{|c|}{ Refocus on planning } \\
\hline Item 5 & & & & & 0.65 & & & & \\
\hline Item 14 & & & & & 0.59 & & & & \\
\hline Item 23 & & & & & 0.43 & & & & \\
\hline Item 32 & & & & & 0.65 & & & & \\
\hline \multicolumn{10}{|c|}{ Positive reappraisal } \\
\hline Item 6 & & & & & & 0.71 & & & \\
\hline Item 15 & & & & & & 0.77 & & & \\
\hline Item 24 & & & & & & 0.53 & & & \\
\hline Item 33 & & & & & & 0.62 & & & \\
\hline \multicolumn{10}{|c|}{ Putting into perspective } \\
\hline Item 7 & & & & & & & 0.59 & & \\
\hline Item 16 & & & & & & & 0.71 & & \\
\hline Item 25 & & & & & & & 0.69 & & \\
\hline Item 34 & & & & & & & 0.77 & & \\
\hline \multicolumn{10}{|c|}{ Catastrophizing } \\
\hline Item 8 & & & & & & & & 0.39 & \\
\hline Item 17 & & & & & & & & 0.75 & \\
\hline Item 26 & & & & & & & & 0.41 & \\
\hline Item 35 & & & & & & & & 0.86 & \\
\hline \multicolumn{10}{|c|}{ Other-blame } \\
\hline Item 9 & & & & & & & & & 0.75 \\
\hline Item 18 & & & & & & & & & 0.76 \\
\hline Item 27 & & & & & & & & & 0.79 \\
\hline Item 36 & & & & & & & & & 0.85 \\
\hline
\end{tabular}

Coefficients are standardized estimates. 
well as for the total scale, with alpha values exceeding 0.70 . These results are comparable with previous adaptations of the instrument. As shown in Table 2, the Brazilian version of the CERQ had the highest reported alphas for the subscales self-blame, acceptance, rumination, and other-blame. The alphas ranged from 0.71 (refocus on planning) to 0.88 (other-blame).

\section{Descriptive data and correlations among subscale means}

Descriptive results and correlations among all nine CERQ subscales are presented in Table 3 . The highest and lowest means were obtained, respectively, on positive refocusing ( $\operatorname{mean}=3.25 ; \mathrm{SD}=1.17$ ), and self-blame (mean $=1.67 ; S D=0.96)$, suggesting that the first strategy was the one used most frequently by the sample, and the second strategy the one used the least.

As expected, weak-to-moderate correlations among the CERQ subscales were found. In general, moderate correlations were found within adaptive and within maladaptive emotion regulation strategies, while weak correlations were found between them. The only associations out of this pattern were between acceptance and rumination $(r=0.46 ; p<0.001)$, acceptance and catastrophizing $(r=0.35 ; \mathrm{p}<0.001)$, and rumination and refocus on planning $(r=0.39, p<0.001)$. The strongest association was found between catastrophizing and rumination $(r=0.67 ; \mathrm{p}<0.001)$.

\section{Correlations between CER strategies and positive/negative affect}

Correlations and partial correlations between all nine subscales of the CERQ and positive and negative affect (measured by the PANAS) are shown in Table 4. Regarding positive affect, significant positive correlations were found with refocus on planning, positive reappraisal, and putting into perspective. However, once the influence of the remaining subscales on each of the factors was controlled by means of

Table 2 - Reliability data of the Cognitive Emotion Regulation Questionnaire (CERQ) subscales in comparison to previous adaptations

\begin{tabular}{|c|c|c|c|c|c|c|c|c|c|c|}
\hline CERQ & $\mathbf{a}^{*}$ & $\begin{array}{c}\text { Original } \\
(\mathrm{N}=611)\end{array}$ & $\begin{array}{c}\text { French } \\
(\mathrm{N}=\mathbf{2 3 0})\end{array}$ & $\begin{array}{c}\text { Spanish } \\
(\mathrm{N}=615)\end{array}$ & $\begin{array}{c}\text { Romanian } \\
(\mathrm{N}=1, \mathbf{0 7 1})\end{array}$ & $\begin{array}{c}\text { Persian } \\
(\mathrm{N}=503)\end{array}$ & $\begin{array}{c}\text { Turkish } \\
(\mathrm{N}=396)\end{array}$ & $\begin{array}{c}\text { Argentinean } \\
(\mathrm{N}=359)\end{array}$ & $\begin{array}{c}\text { Chinese } \\
(\mathrm{N}=791)\end{array}$ & $\begin{array}{l}\text { Peruvian } \\
(\mathrm{N}=345)\end{array}$ \\
\hline 1. Self-blame & 0.86 & 0.75 & 0.78 & 0.61 & 0.69 & 0.69 & 0.72 & 0.69 & 0.76 & 0.58 \\
\hline 2. Acceptance & 081 & 0.76 & 0.68 & 0.64 & 0.71 & 0.64 & 0.74 & 0.59 & 0.77 & 0.58 \\
\hline 3. Rumination & 0.85 & 0.83 & 0.74 & 0.74 & 0.76 & 0.71 & 0.82 & 0.70 & 0.82 & 0.69 \\
\hline 4. Positive refocusing & 0.86 & 0.85 & 0.83 & 0.89 & 0.83 & 0.81 & 0.81 & 0.83 & 0.86 & 0.74 \\
\hline 5. Refocus on planning & 0.71 & 0.86 & 0.81 & 0.83 & 0.80 & 0.79 & 0.81 & 0.66 & 0.90 & 0.61 \\
\hline 6. Positive reappraisal & 0.77 & 0.85 & 0.87 & 0.80 & 0.80 & 0.82 & 0.79 & 0.77 & 0.88 & 0.70 \\
\hline 7. Putting into perspective & 0.79 & 0.82 & 0.83 & 0.83 & 0.75 & 0.79 & 0.75 & 0.70 & 0.76 & 0.66 \\
\hline 8. Catastrophizing & 0.73 & 0.79 & 0.68 & 0.72 & 0.76 & 0.74 & 0.83 & 0.68 & 0.85 & 0.72 \\
\hline 9. Other-blame & 0.88 & 0.82 & 0.80 & 0.79 & 0.75 & 0.81 & 0.82 & 0.82 & 0.86 & 0.69 \\
\hline
\end{tabular}

* Reliability analysis performed using Cronbach's alpha, represented in the table by a.

Original: Garnefski \& Kraaij (2007)5; French: Jermann, et al. (2006) ${ }^{16}$; Spanish: Domínguez-Sánchez, et al. (2011) ${ }^{18}$; Romanian: Perte \& Miclea (2011) ${ }^{12}$; Persian: Abdi et al. (2012) ${ }^{15}$; Turkish: Tuna \& Bozo (2012) ${ }^{17}$; Argentinean: Medrano et al. (2013) ${ }^{13}$; Chinese: Zhu et al. (2008) ${ }^{19}$; Peruvian: Lara \& Medrado $(2016) \cdot{ }^{14}$

Table 3 - Spearman's correlations among the Cognitive Emotion Regulation Questionnaire (CERQ) subscales

\begin{tabular}{|c|c|c|c|c|c|c|c|c|c|c|}
\hline CERQ & Mean (SD) & 1 & 2 & 3 & 4 & 5 & 6 & 7 & 8 & 9 \\
\hline 1. Self-blame & $1.67(0.96)$ & - & & & & & & & & \\
\hline 2. Acceptance & $2.85(1.15)$ & $0.34 *$ & - & & & & & & & \\
\hline 3. Rumination & $2.22(1.06)$ & $0.49 *$ & $0.46^{*}$ & - & & & & & & \\
\hline 4. Positive refocusing & $3.25(1.17)$ & -0.21 & $0.27 *$ & -0.003 & - & & & & & \\
\hline 5. Refocus on planning & $2.96(1.02)$ & $0.26 *$ & $0.44^{*}$ & $0.39 *$ & $0.60 *$ & - & & & & \\
\hline 6. Positive reappraisal & $2.81(1.09)$ & $0.21 *$ & $0.46 *$ & $0.15 *$ & $0.42 *$ & $0.59 *$ & - & & & \\
\hline 7. Putting into perspective & $3.02(1.14)$ & $0.21 *$ & $0.39 *$ & 0.06 & $0.45^{*}$ & $0.41 *$ & $0.57 *$ & - & & \\
\hline 8. Catastrophizing & $1.91(0.86)$ & 0.31 & $0.35^{*}$ & $0.67 *$ & -0.02 & $0.24 *$ & 0.08 & -0.04 & - & \\
\hline 9. Other-blame & $1.88(1.07)$ & $0.21 *$ & $0.23 *$ & $0.34 *$ & $0.12 *$ & $0.24 *$ & $0.10^{+}$ & 0.04 & $0.35^{*}$ & - \\
\hline Total scale & $2.5(0.64)$ & - & - & - & - & - & - & - & - & - \\
\hline
\end{tabular}

$\mathrm{SD}=$ standard deviation.

$* \mathrm{p}<0.001 ;{ }^{+} \mathrm{p}<0.05$. 
partial correlations, the relationship between putting into perspective and positive affect disappeared, and a negative significant correlation between self-blame and positive affect was found. Similarly, when correlating the nine subscales and negative affect, significant positive associations were found between negative affect and acceptance, refocus on planning, putting into perspective, self-blame, rumination, catastrophizing, and other-blame; rumination was the strategy with the strongest association. When partial correlations were conducted, the only relationships with negative affect that were maintained were between refocus on planning, putting into perspective, self-blame, and rumination. Additionally, a new significant negative association was found between negative affect and positive reappraisal.

\section{Discussion}

The ability to regulate emotions is an important factor to understand some psychological processes associated with mental health. ${ }^{14}$ Because of that, the lack of instruments measuring this construct, properly adapted for Brazilian populations, poses obstacles to this field of research. Therefore, the main purpose of this study was to develop a Brazilian version of the CERQ and to evaluate its psychometric properties in a sample of Brazilian university students. Since its development, the CERQ has been translated and adapted into many different languages and populations across the world. In line with those adapted versions, the results of this study indicate that the CERQ is a valid and reliable tool for assessing CER strategies in Brazil.

Confirmatory factor analyses showed that the original underlying nine-factor structure of the CERQ ${ }^{5}$ was replicated and appropriate to explain the data collected using the Brazilian Portuguese translated version. However, differently from the Spanish ${ }^{18}$ and French $^{16}$ versions, but according to the Argentinean ${ }^{13}$ and Peruvian ${ }^{14}$ versions, the second-order model of adaptive and maladaptive strategies was not acceptable, suggesting that the CER strategies would be better explained individually than if grouped according to their adaptability.

Previous studies have already discussed that classifying CER strategies into adaptive and maladaptive is not a good approach to define their effectiveness, ${ }^{13,18}$ since they are qualitatively different and may have different effects on behavior. While some people may react by trying to soften the emotional effect of a stressful or traumatic event, other people may react by trying to indulge it. Additionally, because different events comprise different emotional stimuli, it seems important to raise questions such as whether a strategy can be adaptive or maladaptive in all circumstances. ${ }^{4}$

In line with that, results from correlation analysis with affective variables suggest that refocus on planning and putting into perspective, theoretically considered adaptive strategies, were associated positively with negative affect. Even though there is no clear explanation for these relationships, it is possible to hypothesize that not every strategy will be adaptive, or maladaptive, in all circumstances. Since every emotion is triggered by some stimulus, the effectiveness of

Table 4 - Spearman's correlations and partial correlations between the Cognitive Emotion Regulation Questionnaire (CERQ) subscales and Positive and Negative Affect Schedule (PANAS)

\begin{tabular}{|c|c|c|c|c|}
\hline \multirow[b]{2}{*}{ CERQ } & \multicolumn{2}{|c|}{ Positive affect } & \multicolumn{2}{|c|}{ Negative affect } \\
\hline & $r$ & Partial $r$ & $r$ & Partial $r$ \\
\hline \multicolumn{5}{|l|}{ Adaptive strategies } \\
\hline Acceptance & 0.07 & -0.10 & $0.27 *$ & 0.06 \\
\hline Positive refocusing & 0.04 & 0.01 & 0.08 & 0.02 \\
\hline Refocus on planning & $0.37 *$ & $0.19 *$ & $0.24 *$ & $0.10^{+}$ \\
\hline Positive reappraisal & $0.28 *$ & $0.14^{+}$ & 0.01 & $-0.22 *$ \\
\hline Putting into perspective & $0.18^{*}$ & 0.02 & $0.12 *$ & $0.01^{+}$ \\
\hline \multicolumn{5}{|l|}{ Maladaptive strategies } \\
\hline Self-blame & -0.05 & $-0.12^{+}$ & $0.37 *$ & $0.18^{+}$ \\
\hline Rumination & 0.04 & 0.01 & $0.45 *$ & $0.19 *$ \\
\hline Catastrophizing & 0.02 & 0.00 & $0.33 *$ & 0.04 \\
\hline Other-blame & 0.08 & 0.06 & $0.27 *$ & 0.06 \\
\hline
\end{tabular}

\footnotetext{
${ }^{*} p<0.001 ;{ }^{+} p<0.05$.
} 
regulating strategies will not occur per se, but rather depending on the stimulus that elicited its use. It is probably not possible to presume that the same strategy will be equally effective when facing different emotional stimuli. ${ }^{13}$

Regarding internal consistency, the alpha coefficients of the Brazilian version of the CERQ were moderate to excellent. Since all alpha values were $>0.70$, the results suggest that the instrument may possess stronger internal consistency in most subscales when compared to the French, ${ }^{16}$ Spanish, ${ }^{18}$ Romanian, ${ }^{12}$ Persian, ${ }^{15}$ Turkish, ${ }^{17}$ Argentinean, ${ }^{13}$ and Peruvian ${ }^{14}$ versions, each of which have yielded subscale alphas $<0.70$.

Even though this study showed that the Brazilian Portuguese version of the CERQ has good psychometric properties, some limitations should be mentioned. The present sample consists of university students, who may not represent the general Brazilian population, limiting the generalization of results. Additionally, the only measure of CER used was one of self-report. Future studies should explore the external validity of the CERQ by investigating its factor structure in more representative populations, as well as test its comprehension in samples of low schooling and economic status. Also, other measures evaluating similar constructs, such as structured clinical interviews, peer or family ratings, and direct behavioral assessments should be used to address the common-method variance bias. In this sense, some psychometric aspects of the instrument were not analyzed, so more investigations should be conducted to examine the instrument's stability over time, as well as its convergent and divergent validity.

The main value of the CERQ is that it allows clinicians and researchers to measure a broad variety of cognitive ways of dealing with a wide range of negative, stressful, and traumatic events. Because its strategies have already been associated with psychopathologies, ${ }^{4,12}$ instruments like the CERQ allow for further exploration of the relationship between CER strategies and psychopathological symptoms in order to improve interventions.

\section{Acknowledgements}

The present study was carried out at Programa de Pós-Graduação em Psicologia, Pontifícia Universidade Católica do Rio Grande do Sul (PUCRS), Porto Alegre, RS, Brazil.

The study received financial support from Conselho Nacional de Desenvolvimento Científico e Tecnológico (CNPq/Brazil) through the granting of research scholarships.

\section{Disclosure}

No conflicts of interest declared concerning the publication of this article.

\section{References}

1. Ochsner KN, Gross JJ. The cognitive control of emotion. Trends Cog Sci. 2005;242-9.

2. Gross J]. The emerging field of emotion regulation: an integrative review. Rev Gen Psychol. 1998;2:271-99.

3. Garnefski N, Van den Kommer T, Kraaij V, Teerds J, Legerstee J, Onstein $\mathrm{E}$. The relationship between cognitive emotion regulation strategies and emotional problems: Comparison between a clinical and a non-clinical sample. Eur J Pers. 2002;16:403-20.

4. Garnefski N, Kraaij V, Spinhoven P. Negative life events, cognitive emotion regulation and emotional problems. Pers Individ Dif. 2001;30:1311-27.

5. Garnefski N, Kraaij V. The cognitive emotion regulation questionnaire: Psychometric features and prospective relationships with depression and anxiety in adults. Eur J Psychol Assess. 2007;23:141-9.

6. Schmidt S, Tinti C, Levine LJ, Testa S. Appraisals, emotions and emotion regulation: an integrative approach. Motiv Emot. 2010;34:63-72.

7. Aldao A, Nolen-Hoeksema S, Schweizer S. Emotion-regulation strategies across psychopathology: A meta-analytic review. Clin Psychol Rev. 2010;30:217-37.

8. Martin RC, Dahlen ER. Cognitive emotion regulation in the prediction of depression, anxiety, stress, and anger. Pers Individ Dif. 2005;39:1249-60.

9. Cai W, Pan Y, Zhang S, Wei C, Dong W, Deng G. Relationship between cognitive emotion regulation, social support, resilience and acute stress responses in Chinese soldiers: exploring multiple mediation model. Psychiatry Res. 2017;256:71-8.

10. Garnefski N, van Rood Y, de Roos C, Kraaij V. Relationships between traumatic life events, cognitive emotion regulation strategies, and somatic complaints. J Clin Psychol Med Settings. 2017;24:144-51.

11. Kaczkurkin AN, Zang Y, Gay NG, Peterson AL, Yarvis JS, Borah EV, et al. Cognitive emotion regulation strategies associate with the DSM-5 Posttraumatic Stress Disorder criteria. J Trauma Stress. 2017;30:343-50.

12. Perte A, Miclea M. The Standardization of the Cognitive Emotion Regulation Questionnaire (CERQ) on Romanian Population. Brain Behav. 2011;XV:111-30.

13. Medrano LA, Moretti L, Ortiz Á. Validación del Cuestionario de Regulación Emocional Cognitiva en Universitarios de Córdoba. Psykhe. 2013;22:83-96.

14. Lara SAD, Medrano LA. Propiedades psicométricas del cuestionario de regulación cognitiva de la emociones (CERQ) en estudiantes universitarios de Lima. Psychol Av Discip. 2016;10:53-67.

15. Abdi S, Taban S, Ghaemian A. Social and Cognitive emotion regulation questionnaire : Validity and reliability of the Persian translation of the CERQ (36-item). Procedia Soc Behav Sci. 2012;32:2-7.

16. Jermann $F$, Van Der Linden $M$, D'Acremont $M$, Zermatten A. Cognitive Emotion Regulation Questionnaire (CERQ): Confirmatory factor analysis and psychometric properties of the French translation. Eur J Psychol Assess. 2006;22:126-31.

17. Tuna $E$, Bozo Ö. The Cognitive Emotion Regulation Questionnaire: factor structure and psychometric properties of the Turkish version. J Psychopathol Behav Assess. 2012;34:564-70.

18. Domínguez-Sánchez FJ, Lasa-Aristu A, Amor PJ, Holgado-Tello FP. Psychometric properties of the Spanish version of the Cognitive Emotion Regulation Questionnaire. Assessment. 2011;20:25361.

19. Zhu X, Auerbach RP, Yao S. Psychometric properties of the Cognitive Emotion Regulation Questionnaire: Chinese version. Cogn Emot. 2008;22:288-307.

20. Associação Brasileira de Empresas de Pesquisa. Critério de Classificação Econômica Brasil. 2008.

21. American Psychiatric Association. Diagnostic and Statistical Manual of Mental Disorders, 5th ed. Washington: APA; 2013. 
22. Gray MJ, Litz BT, Hsu JL, Lombardo TW. Psychometric properties of the life events checklist. Assessment. 2004;11:330-41.

23. Weathers FW, Blake DD, Schnurr PP, Kaloupek DG, Marx BP, Keane TM. The Life Events Checklist for DSM-5 (LEC-5) [Internet]. 2013. [cited 2018 Jan 11]. www.ptsd.va.gov.

24. Watson D, Clark LA, Tellegen A. Development and validation of brief measures of positive and negative affect: the PANAS scales. J Pers Soc Psychol. 1988;54:1063-70.

25. Carvalho HW, Andreoli SB, Lara DR, Patrick C], Quintana MI, Bressan $\mathrm{R}$, et al. Structural validity and reliability of the Positive and Negative Affect Schedule (PANAS): Evidence from a large Brazilian community sample. Rev Bras Psiquiatr. 2013;35:169-72.

26. Beaton DE, Bombardier C, Guillemin F, Ferraz MB. Guidelines for the process of cross-cultural adaptation of self-report measures. Spine. 2000;25:3186-91.

27. Pasquali L. Instrumentação psicológica: fundamentos e práticas. Porto Alegre: Artmed; 2010.

28. Stein NR, Mills MA, Arditte K, Mendoza C, Borah AM, Resick PA, et al. A scheme for categorizing traumatic military events. Behav Modif. 2012;36:787-807.
29. Kline RB. Exploratory and confirmatory factor analysis. In: Petscher $Y$, Schatsschneider $C$, editors. Applied quantitative analysis in the social sciences. New York: Routledge; 2013. p. 171-207.

30. Hu LT, Bentler PM. Cutoff criteria for fit indexes in covariance structure analysis: Conventional criteria versus new alternatives. Struct Equ Modeling. 1999;6:1-55.

31. Brown TA. Confirmatory factor analysis for applied research. New York: Guilford; 2015.

\section{Correspondence:}

Julia L. Schäfer

Av. Ipiranga, 6681, Prédio 11

90619-900 - Porto Alegre, RS - Brazil

Tel.: +55 (51) 999486078

E-mail: julialuizaschafer@gmail.com 